stellen. Durch die Ermessenseinräumung nach $\ 99$ Abs. 1 S. 2 VwGO wird ihr die Möglichkeit eröffnet, dem öffentlichen Interesse und dem individuellen Interesse der Prozessparteien an der Wahrheitsfindung in dem vom Untersuchungsgrundsatz beherrschten Verwaltungsprozess den Vorrang vor den Interessen an der Geheimhaltung zu geben. Dazu ist es unerlässlich, dass die Entscheidungserheblichkeit der (vollständigen) Aktenvorlagen förmlich feststeht, vgl. BVerwG, Beschl. v. 22.1.2009-20 F 5.08, juris, und damit eindeutig beantwortet ist. Nur auf der Grundlage einer solchen Feststellung kann die oberste Aufsichtsbehörde die ihr auferlegte besondere Ermessensabwägung auf rechtlich gesicherter Grundlage durchführen.

$\cdots$

DOI: 10.1007/s10357-010-1857-1

\section{Konkurrenzverhältnis \\ der Artenschutzbestimmungen im BJagdG, BNatSchG, TierSchG}

BNatSchG §10 Abs. 1, §42 Abs. 1, §65 Abs. 1, §66 Abs. 2; TierSchG $\S 17$

Es besteht kein genereller Vorrang des Bundesjagdgesetzes gegenüber Vorschriften des Artenschutzes im Bundesnaturschutzgesetz und Tierschutzgesetz.

OLG Köln, Beschluss vom 5.3.2010, 83 Ss 102/09

Dem Angeklagten ist durch die zugelassene Anklageschrift der Staatsanwaltschaft zur Last gelegt worden, sich in drei Fällen wegen Verstoßes gegen das Bundesnaturschutzgesetz und das Tierschutzgesetz strafbar gemacht zu haben, weil er Anfang Januar 2007 eine Lebendfalle und vergiftete Köder in seinem Jagdrevier ausgelegt und dadurch einen Mäusebussard und einen Habicht (Fall 1), wenige Tage später in gleicher Tatbegehungsweise zwei Mäusebussarde und einen Fischreiher (Fall 2) sowie am 16.1.2007 zwei Mäusebussarde mittels vergifteter Fleischstücke getötet habe (Fall 3). Durch Urteil des Amtsgericht Aachen ist der Angeklagte im Fall 1 wegen Tierquälerei in Tateinheit mit vorsätzlichem verbotenen Nachstellen von Tieren streng geschützter Arten zu einer Geldstrafe von 80 Tagessätzen zu je 50,00 Euro verurteilt worden; hinsichtlich der übrigen Taten (Fall 2 und 3) ist er freigesprochen worden ist.

Gegen dieses Urteil haben die Staatsanwaltschaft und der Angeklagte Berufung eingelegt. Hinsichtlich des Freispruchs zu Fall 2 hat die Staatsanwaltschaft ihr Rechtsmittel zurückgenommen.

Das Landgericht hat die Rechtsmittel mit der Maßgabe verworfen, dass es die Tagessatzhöhe auf 30,00 Euro herabgesetzt und dem Angeklagten gestattet hat, die Geldstrafe in monatlichen Raten zu je 100,00 Euro zu zahlen.

Zur rechtlichen Würdigung - gleichzeitig das Ergebnis des Tatgeschehens zusammenfassend - hat die Strafkammer ausgeführt:

,Der Angeklagte hat sich hiernach - nachdem die Verfolgung in der Berufungshauptverhandlung gemäß $\$ 154 \mathrm{a}$ StPO auf Verstöße gegen das Bundesnaturschutz- und Tierschutzgesetz beschränkt worden ist - wegen vorsätzlichen Verstoßes gegen $\$ 66$ Abs. 2 i. V.m. $\$ 65$ Abs. 1 Nr. 1 , 42 Abs. 1 Nr. 1, \$10 Abs. 1 Nr. 10 Buchstabe a) Bundesnaturschutzgesetzt in Tateinheit mit einem Verstoß gegen das Tierschutzgesetz gemäß $\$ 17$ Nr. 1 Tierschutzgesetz schuldig gemacht. Der Angeklagte hat zumindest Mäusebussarden nachgestellt, die zu den im Anhang der betreffenden EG-Verordnung gemäß $₫ 10$ Abs. 2 Nr. 10 Buchstabe a) besonders geschützten Arten gehören. Der Mäusebussard ist durch das Auslegen der vergifteten Köder getötet worden. Darüber hinaus hat der Angeklagte tateinheitlich weiteren Mäusebussarden durch das Aufstellen der Lebendfalle und das Auslegen der Köder nachgestellt.“

Gegen dieses Urteil richtet sich die Revision des Angeklagten.

\section{Aus den Gründen:}

Die Revision ist unbegründet, da die Nachprüfung des Urteils aufgrund der Revisionsbegründung keinen Rechtsfehler zum Nachteil des Angeklagten ergeben hat. Das Rechtsmittel ist daher dem Antrag der Generalstaatsanwaltschaft entsprechend gemäß $₫ 349$ Abs. 2 StPO zu verwerfen.

Insbesondere hat das Landgericht seine Überzeugung von der Täterschaft des Angeklagten rechtsfehlerfrei begründet, wie auch die Generalstaatsanwaltschaft in ihrer Antragsschrift zutreffend ausgeführt hat.

In Ergänzung dieser Antragsschrift merkt der Senat lediglich Folgendes an:

Die Subsumtion des rechtsfehlerfrei festgestellten Sachverhalts im angefochtenen Urteil unter die - im Einzelnen dort angeführten - Vorschriften des Bundesnaturschutzgesetzes und des Tierschutzgesetzes lässt keinen Rechtsfehler zum Nachteil des Angeklagten erkennen.

Was das Verhältnis der Vorschriften des Bundesjagdgesetzes zu den Bestimmungen des Artenschutzes im Bundesnaturschutzgesetz und Tierschutzgesetz anbelangt, schließt sich der Senat der Auffassung an, dass kein genereller Vorrang des Jagdrechts besteht (vgl. zu dieser Auffassung u. a.: VGH Mannheim NuR 2000, 149; RhPfVerfGH NuR 2001, 247; Gassner u. a., BNatSchG, 2. Auflage, \39 Rdnr. 10 ff.; Brocker NuR 2000, 307; anderer Ansicht u. a.: Meyer-Ravenstein AgrarR 2000, 277). Die sog. „Unberührtheitsklausel“" in $\$ 39$ Abs. 2 BNatSchG besagt nur, dass der jeweilige Vorrang der dort angesprochenen Rechtsgebiete nach allgemeinen Auslegungsregeln - insbesondere unter dem Gesichtspunkt der Spezialität - zu bestimmen ist (so zu $\$ 20$ Abs. 2 BNatSchG alter Fassung: RhPfVerfGH a.a. O.; VGH Mannheim a.a. O., jeweils auch unter Hinweis auf die Begründung zum BNatSchG, BT-Drs. 10/5064: „Im Falle konkurrierender Vorschriften der genannten Rechtsbereiche ist die Frage des Vorrangs nach allgemeinen Auslegungsregeln zu entscheiden“, wobei zwischen Vergehen nach den Strafvorschriften des Bundesjagdgesetzes und denjenigen des Bundesnaturschutzgesetzes auch Tateinheit möglich ist (vgl. Pfohl, in Münchener Kommentar zum StGB, \66 BNatSchG Rdnr. 117).

In vorliegender Sache bedarf es keines weiteren Eingehens auf hier in Betracht kommende Konkurrenzverhältnisse.

a) Denn durch die (ausschließliche) Anwendung der Vorschriften des Bundesnaturschutzgesetzes und des Tierschutzgesetzes ist der Angeklagte nicht beschwert.

Würde eine Strafbarkeit nach diesen Vorschriften ausscheiden, wäre er auf der Grundlage der getroffenen Feststellungen nach den vom ihm angeführten Vorschriften des Bundesjagdgesetzes - mit demselben Strafrahmen (Freiheitsstrafe bis zu 5 Jahren oder Geldstrafe, $\$ 38$ Abs. 1 Nr. 2 BJagdG) - zu bestrafen, ggf. wäre sogar die Annahme von Tateinheit mit den in Rede stehenden Vorschriften des Bundesnaturschutzgesetzes und des Tierschutzgesetzes möglich.

Schon wegen der fehlenden Beschwer braucht der Senat der Frage einer Schuldspruchberichtigung in entsprechender Anwendung des $\$ 354$ Abs. 1 StGB nicht nachzugehen (vgl. Meyer-Goßner, StPO, 52. Aufl., \354 Rdnr. 17). Die vom Tatgericht angewendeten Strafvorschriften sind auch nicht etwa völlig verschieden von den in Betracht kommenden Strafvorschriften des Bundesjagdgesetzes; in diesem Fall würde die Berichtigung keine Beschwer voraussetzen (Meyer-Goßner a.a.O.). Sie betreffen im Ergebnis sämtlich den Arten- und Tierschutz.

(Mitgeteilt von Richter am OLG F. Jütte, Köln) 